\title{
PEMODELAN PRODUKSI TANAMAN PANGAN BERDASARKAN KARAKTERISTIK TENAGA KERJA MENGGUNAKAN REGRESI AKAR CIRI
}

\author{
GUSTI NOVIA, IZZATI RAHMI HG \\ Program Studi Matematika, \\ Fakultas Matematika dan Ilmu Pengetahuan Alam, Universitas Andalas, \\ Kampus UNAND Limau Manis Padang, Indonesia, \\ gustinovia@gmail.com,izzatirahmihg@yahoo.com, hyozza@gmail.com
}

\begin{abstract}
Abstrak. Produksi tanaman pangan tentu saja tidak pernah lepas dari peranan tenaga kerja. Penelitian ini bertujuan mengkaji model hubungan terbaik antara karakteristik tenaga kerja terhadap hasil produksi tanaman pangan. Diduga terjadi korelasi yang tinggi antara karakteristik-karakteristik tenaga kerja, sehingga analisis hubungan antara karakteristik tenaga kerja terhadap produksi tanaman pangan dilakukan dengan menggunakan regresi akar ciri. Data yang digunakan merupakan data sekunder yang diperoleh dari Badan Pusat Statistik dan data Statistik Ketenagakerjaan sektor pertanian 2012 yang dikeluarkan oleh Pusat Data dan Sistem Informasi Pertanian (Sekretariat JendralKementrian Pertanian 2013). Berdasarkan hasil analisis data dan pemilihan model terbaik menggunakan eliminasi langkah mundur, diperoleh persamaan

$Y=3.368 .8146,455-0,891 X_{3}-0,600 X_{4}+0,189 X_{5}-2,522 X_{6}+3,340 X_{9}+1,060 X_{12}$

$-3,900 X_{14}-0,017 X_{17}+1,065 X_{19}+0,574 X_{20}+0,260 X_{21}+1,196 X_{23}+0,579 X_{24}$.
\end{abstract}

Jadi, karakteristik tenaga kerja yang berpengaruh terhadap produksi tanaman pangan adalah jumlah tenaga kerja yang tamat $\left(X_{3}\right)$, jumlah tenaga kerja yang tamat SMP $\left(X_{4}\right)$, jumlah tenaga kerja yang tamat SMA $\left(X_{5}\right)$, jumlah tenaga kerja yang tamat SMK $\left(X_{6}\right)$, jumlah tenaga kerja yang berumur 15-19 tahun $\left(X_{9}\right)$, jumlah tenaga kerja yang berumur 30-34 tahun $\left(X_{12}\right)$, jumlah tenaga kerja yang berumur 40-44 tahun $\left(X_{14}\right)$, jumlah tenaga kerja yang berumur 55-59 tahun $\left(X_{17}\right)$, jumlah tenaga kerja yang berusaha sendiri $\left(X_{19}\right)$, jumlah tenaga kerja yang dibantu buruh tidak tetap $\left(X_{20}\right)$, jumlah tenaga kerja yang dibantu buruh tetap $\left(X_{21}\right)$, jumlah tenaga kerja yang merupakan pekerja bebas pertanian $\left(X_{23}\right)$, jumlah tenaga kerja yang merupakan pekerja keluarga $\left(X_{24}\right)$.

Kata Kunci: Analisis regresi, multikolinearitas, regresi akar ciri, eliminasi langkah mundur

\section{Pendahuluan}

Tenaga kerja pertanian tersebar dalam empat subsektor pertanian, dimana penyerapan tenaga kerja terbesar adalah pada subsektor tanaman pangan, perkebunan, peternakan dan terakhir subsektor holtikutura [1]. Tenaga kerja pada masing-masing subsektor tentu saja memiliki berbagai macam latar belakang yang berbeda-beda. Latar belakang para tenaga kerja pada masing-masing subsektor juga akan mempengaruhi bagaimana produktivitas tenaga kerja serta hasil produksi.

Latar belakang tenaga kerja pada subsektor tanaman pangan juga berbeda-beda seperti umur yang berbeda, pendidikan, serta status pekerjaan. Berbagai latar belakang tersebut berpengaruh terhadap hasil produksi tanaman pangan. Beberapa 
latar belakang yang diduga berpengaruh terhadap hasil produksi yaitu umur, pendidikan terakhir, serta status pekerja. Hal ini dapat dijadikan karakteristik yang dapat mempengaruhi produktivitas tenaga kerja tanaman pangan, dimana secara tidak langsung diduga mempengaruhi hasil produksi tanaman pangan.

Untuk menganalisis pengaruh karakteristik tenaga kerja terhadap hasil produksi tanaman pangan dapat digunakan analisis regresi. Metode yang biasa digunakan untuk menduga model analisis regresi adalah Metode Kuadrat Terkecil (MKT). Masalah yang terjadi dalam banyak kasus pendugaan model regresi adalah terdapatnya kolinearitas antara peubah-peubah bebas.

Dalam menganalisa pengaruh karakteristik tenaga kerja terhadap hasil produksi tanaman pangan, diduga terdapat korelasi antar peubah-peubah karakteristik tenaga kerja. Karena itu dalam penelitian ini Metode Regresi Akar Ciri (Latent Root Regression/LRR) dianggap lebih tepat digunakan untuk menduga model regresi jika dibandingkan dengan Metode Kuadrat Terkecil.

\section{Landasan Teori}

\subsection{Analisis Regresi}

Hubungan linear antara peubah tak bebas $Y$ dan peubah bebas $X_{1}, X_{2}, \cdots, X_{k}$ biasanya dimodelkan dalam bentuk [3]

$$
Y=\beta_{0}+X \beta_{1}+X \beta_{2}+\cdots+X \beta_{k}
$$

dimana

$$
\begin{aligned}
Y: & \text { Peubah tak bebas, } \\
\beta_{j}: & \text { Koefisien regresi ke }-j, j=0,1, \cdots, k, \\
X_{j}: & \text { Peubah bebas ke }-j, j=1,2, \cdots, k, \\
\varepsilon: & \text { galat. }
\end{aligned}
$$

Dalam catatan matriks, model ini dinyatakan sebagai [3]:

$$
\mathbf{Y}=\mathbf{X} \beta+\varepsilon,
$$

dimana

$$
\begin{aligned}
& \mathbf{Y}: \text { vektor peubah tak bebas, } \\
& X: \text { matriks rancangan berukuran } n x(k+1), \\
& \beta: \text { vektor koefisian berukuran }(k+1) x 1, \\
& \varepsilon: \text { vektor sisaan berukuran } n x 1 .
\end{aligned}
$$

Untuk menentukan nilai dugaan dari $\beta$ yaitu dengan meminimumkan JKS yang sering disebut dengan Metode Kuadrat Terkecil MKT. Sehingga diperoleh

$$
\beta=\left(X^{\prime} X\right)^{-1}\left(X^{\prime} Y\right) .
$$




\subsection{Kolinearitas}

Adanya kolinearitas dapat dilihat pada nilai VIF (Variance Inflation Factor), yang dirumuskan sebagai

$$
V I F_{j}=1 /\left(1-R_{j}^{2}\right),
$$

dimana $R_{j}^{2}$ adalah koefisien determinasi dari regresi antara peubah bebas ke-j dengan peubah-peubah bebas lainnya. Nilai VIF yang lebih besar dari 10 menunjukkan adanya masalah kolinearitas pada peubah tersebut [5].

\subsection{Regresi Akar Ciri (Latent Root Regression/LRR)}

Regresi akar ciri merupakan metode yang diajukan sebagai perluasan Regresi Komponen Utama. LRR dilakukan dengan menggabungkan matriks data yang berasal dari peubah bebas yang telah dibakukan dengan peubah respons yang telah di bakukan yang dinotasikan sebagai [2]

$$
A=\left[y^{*}: X^{*}\right]
$$

dimana $X^{*}$ adalah matriks $X$ yang telah dibakukan. Pembakuan dilakukan dengan cara

$$
x_{i j}^{*}=\frac{\left(x_{i j}-\bar{x}_{j}\right)}{\left(\sum_{i=1}^{n}\left(x_{i j}-\bar{x}_{j}\right)^{2}\right)^{\frac{1}{2}}},
$$

dimana $y^{*}$ adalah matriks $y$ yang setiap unsurnya telah dibakukan, dengan cara:

$$
y_{j}^{*}=\frac{\left(y_{i}-\bar{y}\right)}{\left(\sum_{i=1}^{n}\left(y_{j}-\bar{y}\right)^{2}\right)^{\frac{1}{2}}},
$$

Dengan demikian, matriks $A^{\prime} A$ merupakan matrik korelasi gandengan. Seperti halnya dalam metode komponen utama, akar ciri dan vektor cirinya kemudian dihitung dengan menyelesaikan persamaan

$$
\left|A^{\prime} A-\lambda_{j} I\right|=0, \operatorname{dan}\left(A^{\prime} A-\lambda_{j} I\right) \gamma_{j}=0, \quad \text { untuk } j=0,1,2, \cdots, k,
$$

dimana

$$
\begin{aligned}
& \lambda_{j}: \text { akar ciri dari } A^{\prime} A \text { dengan urutan } \lambda_{0} \leq \lambda_{1} \leq \ldots \leq \lambda_{k}, \\
& \gamma_{j} \text { : vektor ciri dari } A^{\prime} A \text { yang berpadanan dengan } \lambda_{j} .
\end{aligned}
$$

Dalam regresi akar ciri unsur pertama setiap vektor ciri $\left(\gamma_{j}\right)$ digunakan sebagai tolak ukur kemampuan vektor ciri tersebut dalam meramalkan peubah respons. Semakin besar unsur pertama vektor ciri, semakin bermanfaatlah vektor ciri didalam meramalkan responsnya dan begitu pula sebaliknya. Adanya akar ciri yang kecil menandakan kemungkinan adanya ketidakbebasan linear diantara peubah-peubah bebas. Semakin kecil akar ciri, semakin kuat ketidakbebasan linear tersebut.

Dengan membuang vektor ciri yang akar ciri dan unsur pertama vektor padanannya kecil (pedoman yang diajukan Webster dan rekannya adalah $\lambda_{j} \leq 0.05$ dan $\gamma_{j} \leq 0.10$, maka akan diperoleh persamaan kuadrat terkecil yang telah termodifikasi. Persamaan ini yang dinamakan sebagai persamaan Regresi Akar Ciri [3]. Prosedur termodifikasi ini menghasilkan penduga yang berbias. 
Adapun penduga koefisien regresi dihitung setelah menghapus sejumlah $p-$ 1 untuk akar ciri dan vektor ciri yang teridentifikasi menimbulkan kolinearitas, Penduga kofisien tersebut adalah

$$
\begin{aligned}
\widehat{\beta} & =-\eta \sum_{j=p}^{k} a_{j} \gamma_{j}^{0}, \text { dimana } \\
a_{j} & =\frac{\gamma_{0 j} \lambda_{j}^{-1}}{\left(\sum_{r=p}^{k} \frac{\gamma_{0 r}^{2}}{\lambda_{r}}\right)}, \\
\eta & =\left[\sum_{i=1}^{n}\left(Y_{i}-\bar{Y}\right)^{2}\right]^{\frac{1}{2}}, \text { dengan } \\
r, j & : \text { unsur yang tidak terdapat kolinearitas, } r=p, p+1, \cdots, k, \\
\gamma_{j}^{0} & ; \text { vektor ciri } A^{\prime} A \text { tanpa unsur pertama vektor ciri. }
\end{aligned}
$$

Jumlah kuadrat galat model untuk persamaan kuadrat terkecil termodifikasi adalah

$$
J K G=\eta^{2}\left(\sum_{j=p}^{k} \frac{\gamma_{0 j}^{2}}{\lambda_{j}}\right)^{-1}
$$

JKG model akan digunakan untuk menghitung nilai $F$ pada eliminasi langkah mundur.

\subsection{Prosedur Eliminasi Langkah Mundur}

Eliminasi langkah mundur merupakan salah satu prosedur di dalam pemilihan peubah yang dapat menyusun model terbaik. Langkah-langkah pokok dalam prosedur ini adalah sebagai berikut:

(1) Menghitung JKG yang mengandung semua peubah bebas.

(2) Menghitung nilai F parsial yaitu nilai F untuk peubah yang akan dihapus untuk setiap peubah bebas.

Menurut [2] untuk menentukan peubah bebas mana yang pertama-tama dipertimbangkan untuk dihapus, digunakan persamaan

$$
\begin{aligned}
\mu_{0} & =\eta^{2}\left(\rho_{00}-\frac{\rho_{r 0}}{\rho_{r r}}\right)^{-1}, \text { dimana } r=1,2, \cdots, k, \\
\eta & =\left[\sum_{i=1}^{n}\left(Y_{i}-\bar{Y}\right)^{2}\right]^{\frac{1}{2}}, \\
\rho_{u v} & =\sum_{j=p}^{k} \gamma_{u j} \gamma_{v j} \lambda_{j}^{-1}, \text { dimana } u, v=0,1, \cdots, k .
\end{aligned}
$$

Persamaan diatas diselesaikan untuk mencari $\mu_{0}$ yang merupakan JKG (pada model regresi tanpa peubah $X_{r}$ ). Uji yang biasa dilakukan untuk menentukan apakah peubah yang layak untuk dihapuskan adalah uji $\mathrm{F}$, yang ujinya didefinisikan sebagai

$$
F=\left[\frac{J K G\left(\text { Model } X \operatorname{tanpa} X_{r}\right)}{J K G}-1\right] \frac{(n-k-1)}{t},
$$


dimana

$$
\begin{aligned}
J K G\left(\text { Model } X \operatorname{tanpa} X_{r}\right) & : J K G \text { model regresi tanpa peubah } X_{r}, \\
J K G & : J K G \text { model, } \\
t & : \text { jumlah peubah yang dihapus. }
\end{aligned}
$$

(3) Membandingkan nilai $\mathrm{F}$ parsial terendah, misalnya $F_{L}$, dengan nilai $\mathrm{F}$ bertaraf nyata tertentu dari tabel $F_{\text {tabel }}$ yaitu $F_{\alpha, n-p-1}$, misalnya $F_{0}$. Jika $F_{L}<F_{0}$, buang peubah $X_{L}$ yang menghasilkan $F_{L}$, dari persamaan regresi dan hitung kembali persamaan regresi tanpa menyertakan peubah tersebut, kembali ke langkah 2. Jika $F_{L}>F_{0}$, persamaan regresi tersebut dapat diterima.

Penggunaan akar ciri dan vektor ciri matriks $A^{\prime} A$ memungkinkan analisis ini menampilkan eliminasi langkah mundur dengan perhitungan yang lebih mudah pada langkah-langkah awal. Pada prosedur MKT peubah bebas yang memungkinkan untuk dilakukan penghapusan hanya satu peubah, tetapi pada prosedur LRR sejumlah $t$ peubah bebas mungkin dapat dihapus sekaligus pada langkah awal [2].

\section{Data dan Metode Penelitian}

\subsection{Data}

Data yang digunakan dalam penelitian adalah data sekunder yang diperoleh dari Badan Pusat Statistik dan data Statistik Ketenagakerjaan Sektor Pertanian 2012 yang dikeluarkan oleh Pusat Data dan Sistem Informasi Pertanian, Sekretariat Jendral-Kementrian Pertanian tahun 2013. Peubah tak bebas pada penelitian ini adalah produksi pangan masing-masing provinsi pada tahun 2012. Peubah-peubah bebas yang digunakan adalah peubah-peubah yang terkait dengan jumlah penduduk usia kerja ( $\leq 15$ tahun) yang bekerja di lapangan pekerja utama subsektor tanaman pangan (selanjutnya disebut tenaga kerja) dengan karakteristik-karakteristik tertentu.

Adapun peubah-peubah tersebut adalah: jumlah tenaga kerja yang tidak pernah sekolah $\left(X_{1}\right)$, jumlah tenaga kerja yang tidak tamat $\mathrm{SD}\left(X_{2}\right)$,jumlah tenaga kerja yang tamat SD $\left(X_{3}\right)$, jumlah tenaga kerja tamat SMP $\left(X_{4}\right)$, jumlah tenaga kerja yang tamat SMA $\left(X_{5}\right)$, jumlah tenaga kerja yang tamat SMK $\left(X_{6}\right)$, jumlah tenaga kerja yang tamat DIII $\left(X_{7}\right)$, jumlah tenaga kerja yang tamat $S 1\left(X_{8}\right)$, jumlah tenaga kerja yang berumur 15-19 $\left(X_{9}\right)$, jumlah tenaga kerja yang berumur 20-24 $\left(X_{10}\right)$, jumlah tenaga kerja yang berumur 25-29 $\left(X_{11}\right)$, jumlah tenaga kerja yang berumur 30-34 $\left(X_{12}\right)$, jumlah tenaga kerja yang berumur 35-39 $\left(X_{13}\right)$, jumlah tenaga kerja yang berumur 40-44 $\left(X_{14}\right)$, jumlah tenaga kerja yang berumur $45-49\left(X_{15}\right)$, jumlah tenaga kerja yang berumur 50-54 $\left(X_{16}\right)$, jumlah tenaga kerja yang berumur 55-59 $\left(X_{17}\right)$, jumlah tenaga kerja yang berumur 60 keatas $\left(X_{18}\right)$, jumlah tenaga kerja yang berusaha sendiri $\left(X_{19}\right)$, jumlah tenaga kerja yang dibantu buruh tidak tetap $\left(X_{20}\right)$, jumlah tenaga kerja yang dibantu buruh tetap $\left(X_{21}\right)$, jumlah tenaga kerja yang merupakan karyawan $\left(X_{22}\right)$, jumlah tenaga kerja yang merupakan pekerja bebas pertanian $\left(X_{23}\right)$, jumlah tenaga kerja yang merupakan pekerja keluarga $\left(X_{24}\right)$. 


\subsection{Metode penelitian}

Penelitian ini dilaksanakan dengan tahap-tahap sebagai berikut:

(1) Pemeriksaan terhadap data.

(2) Analisis regresi akar ciri berdasarkan diagram pencar sebelumnya.

(3) Analisis regresi akar ciri dilakukan dengan tahapan sebagai berikut:

(a) Pembakuan terhadap peubah-peubah.

(b) Menentukan matriks $A=\left[y^{*}: X^{*}\right]$.

(c) Menghitung akar $\left(\lambda_{j}\right)$ dan vektor ciri $\left(\gamma_{j}\right)$ dari matriks $A^{\prime} A$, dimana $X^{*}$ adalah matriks $X$ yang telah dibakukan. Pembakuan terhadap setiap unsur $X$ dilakukan dengan cara

$$
x_{i j}^{*}=\frac{\left(x_{i j}-\bar{x}_{j}\right)}{\left(\sum_{i=1}^{n}\left(x_{i j}-\bar{x}_{j}\right)^{2}\right)^{\frac{1}{2}}},
$$

dan $y^{*}$ adalah matriks $y$ yang telah dibakukan yang setiap unsurnya akan dibakukan dengan cara

$$
y_{j}^{*}=\frac{\left(y_{i}-\bar{y}\right)}{\left(\sum_{i=1}^{n}\left(y_{j}-\bar{y}\right)^{2}\right)^{\frac{1}{2}}} .
$$

(d) Memisahkan unsur pertama dari setiap vektor ciri dari matriks $A^{\prime} A\left(\gamma_{0 j}\right)$.

(e) Menghapus nilai akar ciri $\left(\lambda_{j}\right)$ dan nilai mutlak vektor ciri unsur pertama padanannya $\left|\gamma_{0 j}\right|$ yang tidak memenuhi pedoman. Pedoman yang berlaku $\lambda_{j} \leq 0.05$ dan $\gamma_{0 j} \leq 0.01$ dengan $j=1,2, \cdots, k+1$. Selanjutnya dilakukan pendugaan model, dengan terlebih dahulu menghitung koefisien menggunakan

$$
\widehat{\beta}=-\eta \sum_{j=p}^{k} a_{j} \gamma_{j}^{0},
$$

dimana

$$
\begin{aligned}
a_{j} & =\frac{\gamma_{0 j} \lambda_{j}^{-1}}{\left(\sum_{r=p}^{k} \frac{\gamma_{0 r}^{2}}{\lambda_{r}}\right)}, \\
\eta & =\left[\sum_{i=1}^{n}\left(Y_{i}-\bar{Y}\right)^{2}\right]^{\frac{1}{2}} \cdot \\
r, j & =\text { unsur yang tidak terdapat koliearitas } r=p, p+1, \cdots, k, \\
\gamma_{j}^{0} & =\text { vektor ciri } A^{\prime} A \text { tanpa unsur pertama vektor ciri. }
\end{aligned}
$$

(4) Melakukan eliminasi langkah mundur untuk memilih peubah berpengaruh untuk membuat model pendugaan yang lebih baik dari model sebelumnya.

(5) Melakukan interpretasi terhadap analisis data yang telah dilakukan.

\section{Pembahasan}

\subsection{Diagram Pencar}

Diagram pencar yang diperoleh menunjukkan umumnya plot cenderung membentuk garis lurus, artinya terdapat hubungan yang linear antara karakteristik-karakteristik 
tenaga kerja dengan produksi tanaman pangan. Sehingga dari kecendrungan tersebut dapat diputuskan bahwa model yang dapat mewakili pola tersebut adalah model linear.

\subsection{Korelasi Peubah}

Korelasi menunjukkan adanya hubungan yang cukup erat diantara peubah-bebas tersebut. Adanya kolinearitas antar peubah bebas juga didukung oleh nilai VIF. Dapat kita lihat semua peubah bebas memiliki nilai VIF yang lebih dari 10, hal ini merupakan indikasi terjadinya kolineariatas pada peubah-peubah. Hal ini dapat dilihat pada Gambar 1 berikut.

\begin{tabular}{|c|c|c|c|c|c|}
\hline Peubah & Nilai VIF & Peubah & Nilai VIF & Peubah & Nilai VIF \\
\hline$X_{1}$ & 447,114 & $X_{9}$ & 615,962 & $X_{17}$ & $8.399,684$ \\
\hline$X_{2}$ & 197,897 & $X_{10}$ & $1.158,278$ & $X_{18}$ & 1.214 .428 \\
\hline$X_{3}$ & 495,440 & $X_{11}$ & $3.145,456$ & $X_{19}$ & 98,382 \\
\hline$X_{4}$ & $1.740,061$ & $X_{12}$ & 556,362 & $X_{20}$ & $2.085,337$ \\
\hline$X_{5}$ & 50,116 & $X_{13}$ & $2.666,229$ & $X_{21}$ & 87,909 \\
\hline$X_{6}$ & 97,491 & $X_{14}$ & $10.591,571$ & $X_{22}$ & 288,324 \\
\hline$X_{7}$ & 51,698 & $X_{15}$ & $5.231,695$ & $X_{23}$ & 770,946 \\
\hline$X_{8}$ & 67,951 & $X_{16}$ & $1.197,479$ & $X_{24}$ & $1.856,280$ \\
\hline
\end{tabular}

Gambar 1. Histogram Tabel 4.4.1, dengan $n=33$

\subsection{Analisis Regresi Akar Ciri}

Analisis ini dilakukan sebagai metode alternatif dalam pendugaan koefisien regresi pada kondisi terdapat multikolinearitas. Pada tahap awal dilakukan pembakuan terhadap peubah bebas dan peubah tak bebas. Tahap berikut adalah menghitung akar ciri $\lambda_{j}$ dan vektor ciri $\gamma_{j} A^{\prime} A$. Setelah akar ciri dan vektor ciri dari matrik $A^{\prime} A$ diperoleh, tahap selanjutnya adalah memisahkan vektor ciri unsur pertama. Gambar 1 memperlihatkan akar ciri dan vektor ciri padanannya yang diurutkan berdasarkan nilai akar ciri terbesar.

Setelah memisahkan unsur pertama vektor ciri $\gamma_{0 j}$ dari matriks $A^{\prime} A$, selanjutnya adalah menghapus vektor ciri unsur pertama yang berpadanan dengan akar ciri $\leq 0,05$ dan memiliki unsur pertama yang memenuhi $\left|\gamma_{0 j}\right| \leq 0,10$. Dari Gambar 1 diketahui bahwa untuk $j=1,2, \cdots, 6$ nilai-nilai akar ciri $\lambda_{j} \leq 0,05$, sedangkan nilai unsur pertama vektor ciri $\left|\gamma_{0 j}\right|<0.10$ ini menunjukkan keenam nilai tersebut disarankan untuk dibuang. Begitu juga untuk $j=8,9, \cdots, 13$ nilai-nilai akar ciri $\lambda_{j} \leq 0,05$ dan nilai unsur pertama vektor ciri padanannya $\left|\gamma_{0 j}\right|<0.10$, ini menunjukkan keenam nilai tersebut juga disarankan untuk dibuang. Pemeriksaan berikutnya menunjukkan bahwa $\lambda_{j}=0,0016 \leq 0,05$ menandakan adanya masalah kesingularan, akan tetapi $\gamma_{0 j}=0,1170>0,10$ menandakan keteramalan yang cukup memadai, sehingga vektor ini tetap dipertahankan.

Selanjutnya untuk menduga model regresi, terlebih dahulu kita menghitung koefisien penduga regresi. Koefisien penduga regresi yang diperoleh dapat dilihat pada 
Gambar 2 berikut.

\begin{tabular}{|c|c|c|}
\hline$j$ & $\lambda_{j}$ & $\left|\gamma_{0 j}\right|$ \\
\hline 24 & 20,6305 & 0,20242 \\
\hline 23 & 1,6093 & 0,13271 \\
\hline 22 & 1.0524 & 0,13057 \\
\hline 21 & 0,6776 & 0,289795 \\
\hline 20 & 0,3341 & 0,01273 \\
\hline 19 & 0,2818 & 0,08426 \\
\hline 18 & 0,1467 & 0,352372 \\
\hline 17 & 0,0796 & 0,05124 \\
\hline 16 & 0,0564 & 0,636923 \\
\hline 15 & 0,0412 & 0,235433 \\
\hline 14 & 0,0303 & 0,434339 \\
\hline 13 & 0,0203 & 0,02527 \\
\hline 12 & 0,0142 & 0,01416 \\
\hline 11 & 0,0109 & 0,057154 \\
\hline 10 & 0,0047 & 0,005271 \\
\hline 9 & 0,0028 & 0,09199 \\
\hline 8 & 0,0026 & 0,09364 \\
\hline 7 & 0,0016 & 0,11706 \\
\hline 6 & 0,0013 & 0,02937 \\
\hline 5 & 0,0009 & 0,06509 \\
\hline 4 & 0,0004 & 0,059935 \\
\hline 3 & 0,0002 & 0,04049 \\
\hline 2 & 0,0001 & 0,04234 \\
\hline 1 & 0,0001 & 0,062066 \\
\hline P & 0,0000 & 0,074424 \\
\hline
\end{tabular}

Gambar 2. Histogram Tabel 4.4.2 n=33

Dari Tabel 4.4.3 dapat diperoleh model persamaan regresi yang dibakukan yaitu

$$
\begin{array}{rl}
Y=1 & .931 .006 Z_{1}+158.631,5 Z_{2}+2.686 .311 Z_{3}+2.204 .6854 Z_{4}-4.740 .699 Z_{5}+6.723 .314 Z_{6} \\
& +2.982 .323 Z_{7}-2.823 .436 Z_{8}-3.689 .554 Z_{9}+6.836 .452 Z_{10}-21.000 .000 Z_{11}+20.005 .909 Z_{12} \\
& -4.306 .745 Z_{13}-24.000 .000 Z_{14}-10.000 .000 Z_{15}+56.852 .597 Z_{16}-5.112 .343 Z_{17}+15.957,65 Z_{18} \\
& +790.639,6 Z_{19}-19.000 .000 Z_{20}-3.112 .281 Z_{21}+8.641 .203 Z_{22}-11.000 .000 Z_{23}-23.000 .000 Z_{24} .
\end{array}
$$

\subsection{Prosedur Langkah Mundur}

Setelah mendapatkan model regresi, dilakukan prosedur eliminasi langkah mundur untuk menghasilkan pendugaan yang lebih baik. Dengan Melakukan eliminasi langkah mundur pada peubah-peubah yang nilai $\mu_{0}$ terkecil, maka diperoleh peubah yang dikeluarkan secara berurutan adalah: $X_{18}, X_{7}, X_{2}, X_{8}, X_{11}, X_{16}, X_{17}, X_{22}$, 


\begin{tabular}{|c|c|c|c|c|c|}
\hline $\begin{array}{l}\text { Koefi } \\
\text { sien }\end{array}$ & $\begin{array}{c}\text { Nilai } \\
\text { Koefisien }\end{array}$ & $\begin{array}{l}\text { Koefi } \\
\text { sien }\end{array}$ & $\begin{array}{c}\text { Nilai } \\
\text { Koefisien }\end{array}$ & $\begin{array}{c}\text { Koefi } \\
\text { sien }\end{array}$ & Nilai Koefisien \\
\hline$b_{1}$ & 15.931 .006 & $b_{9}$ & -3.689 .554 & $b_{17}$ & -5.112 .343 \\
\hline$b_{2}$ & $158.631,5$ & $b_{10}$ & 6.836 .452 & $b_{18}$ & $15.957,65$ \\
\hline$b_{3}$ & 26.861 .311 & $b_{11}$ & -21.000 .000 & $b_{19}$ & $790.639,6$ \\
\hline$b_{4}$ & 22.046 .854 & $b_{12}$ & 20.005 .909 & $b_{20}$ & -19.000 .000 \\
\hline$b_{5}$ & -4.740 .699 & $b_{13}$ & -4.306 .745 & $b_{21}$ & -3.112 .281 \\
\hline$b_{6}$ & 6.723 .314 & $b_{14}$ & -24.000 .000 & $b_{22}$ & 8.641 .203 \\
\hline$b_{7}$ & 2.982 .323 & $b_{15}$ & -10.000 .000 & $b_{23}$ & -11.000 .000 \\
\hline$b_{8}$ & -2.823 .436 & $b_{16}$ & 56.852 .597 & $b_{24}$ & -23.000 .000 \\
\hline
\end{tabular}

Gambar 3. Histogram tabel $4.4 .3 \mathrm{n}=33$

$X_{10}, X_{13}, X_{15}$. Maka peubah-peubah yang dapat dimasukan ke dalam model ada 13 peubah. Prosedur langkah mundur yang dilakukan dengan analisis regresi akar ciri menghasilkan persamaan regresi dengan dengan sembilan belas peubah yaitu: jumlah tenaga kerja yang tamat SD $\left(X_{3}\right)$, jumlah tenaga kerja yang tamat SMP $\left(X_{4}\right)$, jumlah tenaga kerja yang tamat SMA $\left(X_{5}\right)$, jumlah tenaga kerja yang tamat SMK $\left(X_{6}\right)$, jumlah tenaga kerja yang berumur 15-19 tahun $\left(X_{9}\right)$, jumlah tenaga kerja yang berumur 30-34 tahun $\left(X_{12}\right)$, jumlah tenaga kerja yang berumur 40-44 tahun $\left(X_{14}\right)$, jumlah tenaga kerja yang berumur $55-59$ tahun $\left(X_{17}\right)$, jumlah tenaga kerja yang berusaha sendiri $\left(X_{19}\right)$, jumlah tenaga kerja yang dibantu buruh tidak tetap $\left(X_{20}\right)$, jumlah tenaga kerja yang dibantu buruh tetap $\left(X_{21}\right)$, jumlah tenaga kerja yang merupakan pekerja bebas pertanian $\left(X_{23}\right)$, jumlah tenaga kerja yang merupakan pekerja keluarga $\left(X_{24}\right)$. Hal ini menunjukkan tiga belas karakteristik tersebut berpengaruh nyata terhadap lajunya hasil produksi tanaman pangan.

\section{Penutup}

Berdasarkan hasil analisis data dan pemilihan model terbaik menggunakan eliminasi langkah mundur, diperoleh persamaan

$$
\begin{aligned}
Y= & 3.368 .8146,455-0,891 X_{3}-0,600 X_{4}+0,189 X_{5}-2,522 X_{6}+3,340 X_{9}+1,060 X_{12} \\
& -3,900 X_{14}-0,017 X_{17}+1,065 X_{19}+0,574 X_{20}+0,260 X_{21}+1,196 X_{23}+0,579 X_{24} .
\end{aligned}
$$

Jadi, karakteristik tenaga kerja yang berpengaruh terhadap produksi tanaman pangan adalah jumlah tenaga kerja yang tamat SD $\left(X_{3}\right)$, jumlah tenaga kerja yang tamat SMP $\left(X_{4}\right)$, jumlah tenaga kerja yang tamat SMA $\left(X_{5}\right)$, jumlah tenaga kerja yang tamat SMK $\left(X_{6}\right)$, jumlah tenaga kerja yang berumur 15-19 tahun $\left(X_{9}\right)$, jumlah tenaga kerja yang berumur 30-34 tahun $\left(X_{12}\right)$, jumlah tenaga kerja yang berumur 40-44 tahun $\left(X_{14}\right)$, jumlah tenaga kerja yang berumur 55-59 tahun $\left(X_{17}\right)$, jumlah tenaga kerja yang berusaha sendiri $\left(X_{19}\right)$, jumlah tenaga kerja yang dibantu buruh tidak tetap $\left(X_{20}\right)$, jumlah tenaga kerja yang dibantu buruh tetap $\left(X_{21}\right)$, jumlah tenaga kerja yang merupakan pekerja bebas pertanian $\left(X_{23}\right)$, jumlah tenaga kerja yang merupakan pekerja keluarga $\left(X_{24}\right)$. 


\section{Ucapan Terima kasih}

Penulis mengucapkan terima kasih kepada Ibu Hazmira Yozza, M.Si, Bapak Dr. Dodi Devianto, Ibu Dr. Maiyastri, dan Ibu Dr. Susila Bahri yang telah memberikan masukan dan saran sehingga paper ini dapat diselesaikan dengan baik.

\section{Daftar Pustaka}

[1] Anonim. 2013. Statistik Ketenagakerjaan Sektor Pertanian. Pusat Data dan Sistem Informasi Pertanian Sekretariat Jendral-Kementrian Pertanian, jakarta.

[2] Rusdi, A. Analisis Regresi. Jurnal Analisis Regresi. 1 - 14

[3] Steel, R.G.D and James H.Torrie. Prinsip Dan Prosedur Statistika. Gramedia, Jakarta.

[4] Draper, Norman and Harry Smith. 1992. Analisis Regresi Terapan. Gramedia, Jakarta.

[5] Myers, R.H and Janet S.M. 1991. A First Course In The Theory Of Linear Statistical Models. PWS-Kent Publishing Company, Boston.

[6] Alamsyah, A. 1999. Penerapan Regresi Akar Ciri Pada Analisa Produk Domestik Regional Bruto. Bandung. 